\title{
The Analysis of Fantasy and Representation of Female on Gay and Male Homoerotic Relationships in the Yaoi Genre
}

Bakhrul Khair Amal ${ }^{1}$, Supsiloani' ${ }^{2}$ Daud $^{3}$, Dina Ampera ${ }^{4}$ and Muhammad Natsir 5 1,2,3,4,5 Universitas Negeri Medan, Indonesia

\begin{tabular}{l}
\hline \hline ARTICLE INFO \\
\hline \hline Article history: \\
Received: Jun 28. 2021 \\
Revised: Aug 27, 2021 \\
Accepted: Sep 15, 2021 \\
\hline
\end{tabular}

Keywords:

Fantasy,

Relationship,

Homoerotic

\section{Clonflict of Interest:}

\section{None}

\section{Funding:}

None

\begin{abstract}
The research aims to analyze the analysis of fantasy and representation of female on gay and male homoerotic relationships in the Yaoi Genre. This research uses an ethnographic approach, which is one of the qualitative research methods. The results of this study indicate that Fujoshi's background likes love stories between men is certainly different. But from this study it is found that there are a number of similarities, such as being Fujoshi because they initially like manga and anime, those who were curious about the Yaoi Genre, and those who feel bored with the love story between men and women, as well as various other reasons that made them finally addicted romance between men to have sexual fantasies between men.
\end{abstract}

Corresponding Author: Bakhrul Khair Amal, Social Science Department, Technic Department, English Department, Universitas Negeri Medan. E-mail: b4khrul.4m4l@gmail.com

This is an open access article under the CC BY-SA 4.0 international license.

\section{Introduction}

When viewed from its cultural traditions, the actual existence of LGBT people in Indonesia has existed since pre-Islamic times (Boellstorff, 2005). Some religious rites and cultural traditions of Indonesia uphold the diversity of sexuality. One of them is the bissu priest of the Bugis who is generally a male transsexual who has sex with men. There is also a warok-gemblak tradition in East Java which requires a warok (male reog player) to take a boy as a gemblak and educate him as a prospective warok. One form of education that must be taken by a gemblak to become a warok is to have sex with his warok. These traditions were then slowly displaced along with the entry of Islamic teachings into Indonesia and stopped during the crushing period of the G30S PKI. In Indonesia it is not difficult to find women who become Fujoshi (women fans of love relationships between men) so that the term Fujoshi is familiar to certain groups in Indonesia such as Japanese manga and anime fans. Therefore the case regarding Fujoshi is interesting to study because currently in cyberspace it is easy to find Indonesian women who love Yaoi and there has not been much research on Fujoshi in Indonesia. In Japan, the issue of gay is not strange or taboo, even the media in Japan illustrate that gay is a common thing, it is proven easily to find gay stories in several dramas, anime 
(cartoons), manga (comics) or films originating from Japan. These media often raise themes about homosexuality that occur in men, although sometimes it does not become the main story (Triana, 2012). Greenberg (2009) refers to Fujoshi as female Yaoi fans which means women fans of Yaoi (boy's love) genre stories Fujoshi enjoys imagination related to things that would happen if male characters from manga and anime or sometimes even something that came from the real world like male idols loving each other. For example, researchers found that there was a lot of Fujoshi in the comic community at UI. From the information which is one of its members said that almost $80 \%$ of women in the community are Fujoshi. Not infrequently they write stories in the form of short stories or serialized stories that are often called ff (fanfictions) and roleplay which plays the character of the Yaoi they enjoy and seems to be the character. But even though it is easy to meet Fujoshi around us, researchers prefer to make observations in cyberspace and online interviews because all the Fujoshi researchers who were interviewees immediately acted shy and less open when interviewed. Some even dislike and do not want to answer when researchers ask their fantasies and sexual representations of Yaoi. Different from what researchers found during interviews through cyberspace. They are very open to telling their fantasies and sexual representations of Yaoi even though some of them are hiding their real identities. Based on this background, this research focuses more on the background of Fujoshi who is fond of love stories between men, especially in the Yaoi genre, which can easily be found in cyberspace.

\section{Literature Review}

\section{Sexual Fantasy Concepts}

Nobody can prevent or prevent others from doing fantasy activities. Everyone has the right to fantasize, including fantasies related to sexual activity. The purpose of sexual fantasy is a deliberate or unintentional activity of someone to present an illusion that is closely related to sexual activity. Someone who already has physiological maturity, basically can already do sexual fantasy. Sexual fantasies can arise at any time accidentally or intentionally. A teenager who has not or already has a boyfriend can immediately imagine the desire to engage in sexual activity. Sexual fantasy will encourage someone to realize sexual desire. But sexual fantasies can arise because of the urge of sexual arousal in a person. Sexual fantasy can be continued with real sexual behavior, such as kissing, hugs and even sexual relations with a girlfriend or love partner. As a doctor who understands the characteristics of the development of sexual libido, Sigmund Freud recognizes that sexual fantasies have occurred in children during the phallic period. Although the object of children's sexual fantasy is still simple, that is related to both parents, sexual fantasy is really a reality (Hall, Lindsay \& Campbell, 1998). Stepping on adolescence and adulthood, sexual fantasy is considered as the right way to channel the needs of the most personal sexual libido cheaply, safely and comfortably. With sexual fantasies, not infrequently a man or woman will continue to do masturbation or masturbation activities so that they achieve sexual satisfaction (orgasm). Even those who are married, but are unable to achieve sexual satisfaction during sexual relations with their sex partners, they often carry out sexual fantasies with the aim of achieving orgasm in person (Miracle, Miracle \& Baumeister, 2003).

\section{Concept of Representation}

Representation means using language to express something meaningfully, or presenting to others. Representations can be in the form of words, images, sequences, stories, etc. that represent ideas, emotions, facts, and so on. Representation depends on existing signs and images that are culturally understood, in language learning and in various markings or in a reciprocal textual system. This is through the function of the 'representing' sign that we know and study reality (Hartley, 2010: 265). Representation also means the concepts used in the meaning process through the tagging system available in the form of dialogue, writing, video, film, etc. In summary, representation is the production of meaning through language. According to Stuart Hall representation is one of the important practices of producing culture. Culture is a very broad concept, culture involves 'sharing experiences'. A person is said to be from the same culture if the people there share the same experience, share the same cultural codes, speak the same language and share the same concepts (Hall in Key Newsletter, 2000). Through representation, a meaning is produced and exchanged between members of the community. So it can be said that, a brief representation is one way to produce meaning. Representation works through a representation system. This representation system consists of two important components, namely concepts in mind and language. These two components are interrelated. The concept of something that we have in our mind, makes us know the meaning of that thing. However, meaning cannot be communicated without language. According to Stuart Hall. Members of the same culture must share concepts, images, and ideas which enable them to think and feel about the world in roughly similar ways. They must share, broadly speaking, the same 'cultural codes'. In this sense, thinking and feeling are themselves 'system of representations'. 


\section{Various Representations of Fujoshi's Sexual Fantasy Against Yaoi}

\section{Fanfiction}

Fanfiction is a fiction written by fans with the main character of the fanfiction being their idol. In cyberspace such as Facebook, Twitter, personal blogs very many fanfiction stories are easily found with various genres, which fabricate fanfiction, ranging from professional to amateur. The length of fanfiction also varies, some are like short stories and there are also those that like cerbung have many parts. Fanfiction written by fans for fans. Like fanfiction written by fujoshi, made to be read by other Fujoshi. Anyone is free if you want to make fanfiction, there is no certain category to be a requirement for someone to write fanfiction. Usually they spread the fanfiction that they make their personal social account without having to get paid from anyone. Many of Fujosh who like to make Fanfiction. Fanfiction is one way of Fujoshi writing their imagination about yaoi into story form. Fanfiction is a fictional story created by fans based on an existing story, character or setting. Fanfic can apply to films, comics, novels, celebrities and other famous characters. Fanfic plot is the result of the fans' imagination. The emergence of many Fujoshi who started trying to write a fanfiction of the Yaoi genre in cyberspace also often made many other themes emerge. One of them is a fantasy-themed fanfiction in which the author creates his own world. A number of times this research has found this themed yaoi story with the uke storyline of similar couples being able to get pregnant and have children. In real life it is not possible if a truly male can get pregnant and have children. But the story with a plot like this is quite popular with the reader because it gives pleasure to the reader when the uke of the Yaoi story can have a child. Another example of a fantasy theme is that the main character turns out to be an alien, vampire, or from the past who is stuck in the future. Yaoi fanfiction with this theme will present the reader with new things but still carry the core of the yaoi genre itself.

\section{Roleplay}

Roleplayer or commonly abbreviated as RP is a world where someone parodies his bias / idol. usually, roleplayer is closely related to the name 'K-Pop'. And now many roleplayer agencies are mushrooming and offering someone to parody their biases / idols besides k-pop, for example western, Japanese, Indonesian artists, etc. Agency roleplay is a container that gathers people who want to portray their idol. Accounts that serve as the main account / account center collection of several roleplayer acc. There are a lot of agency roleplay in cyberspace, which this research often sees roleplay often played on social networking sites, such as Facebook, Twitter and others. Playing roleplayer is usually free to want to post anything, then can find a partner according to the desired idol pair and will usually date through the timeline, but, not a real courtship but just a relationship status between roleplayer. In the world of roleplayer almost the same as in real life, the only difference is that we play the role of being biased / idol that we like. One of the rules of playing rolepaly is having to hide your own identity. We must as much as possible act as a bias / idol that we play. In roleplay it is usually allowed to transgender. So a woman can RP her boyfriend idols and vice versa. Like Fujoshi, there are many who play their male idol RPs and look for their RP partners as well as those who play RP as men. In every RP they usually have an agency or not. For those who have an agency, there are those who are allowed to do transgender. Sometimes some Fujoshi is forced to lie as a man because he wants to play roleplay as a man while the agency does not allow transgender.

\section{Idol Pairing}

For people who have an idol and declare themselves to be fans, they often pair their idols. Idol pairing is pairing an idol with someone who is considered or expected to be the idol couple. Quite often Fujoshi also often do this. Most Fujoshi pair his male idols with the same sex, often the reason is because he is not willing to idol with other women and if a male idol who looks paired with a handsome idol also just feels right and suitable. One example is an idol couple who is not dating but is often paired by Fujoshi and his fans, a member of the Korean boy band DBSK. From the beginning of the debut, boy band members named Kim Jaejoong and Jung Yunho were often paired as lovers. Even fans often edit their photos like kissing or making their fanart like having sex. The name that fans made for this couple is "YunJae couple" which is a combination of the names Yunho and Jaejung. Why is his name YunJae not JaeYun? Because in this couple Yunho is seme, who acts as the man while Jejung acts as the uke, as the woman because Jeajung's face looks beautiful in Fujoshi's eyes while Yunho is considered masculine.

\section{Fans concept}

Fans deal with fandoms, which cover a variety of fields, that interest people, ranging from music, sports, and animation to fashion. Fiske explained the fandom as follows. Quote: Fandom ... selects from the repertoire of mass-produced and mass-distributed entertainment certain performers, narratives or genres and takes them into the culture of a self-selected fraction of people. They are then reworked into an intensely pleasurable, intensely signifying popular culture that is both similar to, yet significantly different from, the culture of more 'normal' popular audiences.... [Fandom] is ... associated with the cultural tastes of subordinated 
formations of the people, particularly those thrown by any combination of gender, age, class and race (Sandvoss, 2005: 7). From the above understanding Sandvoss in his book Fans: The Mirror of Consumption explains that Fandom brings its own satisfaction to Fans who are part of the fandom. The fans in question are the fans turning popular things into entertainment for them into a means of fulfilling their satisfaction. This action is associated with groups that experience oppression or restrictions. The influence of the social pressure of these fans influenced them to find a place to escape for a moment, making the entertainment as a means of their fantasy, even making it as a means of resistance. In addition, fandom is also a means of selfreflection of fans and also as an extension of the identity of the fans. Different from the general assumption that fictional works with LGBT themes will only be read by those who identify themselves as LGBT, in fact these kinds of fiction are even more favored by those who claim to be heterosexual, especially by heterosexual women (Bauer, 2012). Those who read LGBT romantic fiction mostly claimed to start glancing at these types of readings because they were bored reading heterosexual romance stories that felt monotonous and trying to find alternative stories that had different patterns, or because they were not satisfied with the storyline they were reading to find alternative plot from the story that suits their will. However, the longer and more regularly reading LGBT romantic fiction, they claim to be more able to accept the existence of these people. Educators have long believed the formulation of reading fiction that can change the reader's attitude. Cognitive dissonance obtained by the reader when reading a story that contains persuasive messages is believed to be able to change the attitude of the reader (Haddock \& Maio, 2004). So this also becomes interesting to study, because even though the number of LGBT-themed romantic fiction is increasing and the reader market is getting bigger, but when viewed on a national scale, this development has not yet seemed to influence public acceptance of LGBT people in Indonesia (Abraham, 2008). This dynamic occurs mainly because the attitude of the Indonesian people towards LGBT has a lot to do with personal beliefs rooted in the culture of heterosexism in society. Personal beliefs (according to Paluck (2009) are considered more difficult to change than attitudes based on evaluation of feelings. Therefore, researchers want to see the extent to which LGBT romantic fiction exposure can make a connoisseur of LGBT fiction empathize with the characters in it and whether the two things have a relationship with readers' attitudes towards LGBT issues in the real world.

\section{Overview of Yaoi}

Yaoi, also known as Boys' Love, is a popular term in Japanese that refers to the genre of fiction media publishing that focuses on relationships between men that are homoerotic or homoromantic. Yaoi is generally intended and made by women. Some Westerners consider yaoi to be the same as shōnen-ai, which contains almost the same themes; however, shōnen-ai material is not sexually explicit. The yaoi phenomenon has spread beyond Japan: for example, the emergence of what is now called "American Yaoi". Most Yaoi are made by women, for women. That Yaoi is a product of a cross between two taboo cultures which is quite universal: homosexuality and women's freedom of sexual expression. The contents of yaoi range from romantic situations with moderate adult material to subgenres containing fetishism, including anthropomorphism, cosplay, non-consensual or "non-con" sex, monsters, incest, orgies, shotacon, and various other taboo illustrations about homosexuality. The use of the term yaoi is quite diverse. Some insist that this term should be used only for doujinshi, while others claim that this term only refers to material published by Japanese publishers who specialize in yaoi. However, the majority of yaoi fans use the term for any manga and anime with a theme of male homosexuality. Although Yaoi is sometimes used to refer to male homosexual substances in films and print media, specifically in works created by women, this use is generally considered an abuse of the term. Japanese professional artists, such as Kodaka Kazuma, are careful to distinguish their work as "Yaoi", not "gay", when two parties in a yaoi relationship are often referred to as seme ("attacker") and Uke ("recipient"). Although the term is derived from martial arts, both have been used in sexual contexts for centuries and do not contain negative connotations. Seme is derived from the Japanese verb semeru ("to attack") and uke from the verb Ukeru ("to accept"). Although gays usually use the terms top and bottom, seme and uke are more similar to "thrower" and "catcher". Seme is often presented as a stereotype of men in anime and manga culture: calm, physically strong, and / or protective. Seme usually have stronger jaws, shorter hair, and a more masculine appearance than Uke. Uke are usually more androginus or feminine in appearance and often have smaller bodies and sometimes unrealistically have behaviors that tend to be like girls. The Uke usually falls in love before the seme. Although these stereotypes are very common, not all Yaoi works are like that. For example, some stories published by Be $\mathrm{x}$ Boy feature stories with themes such as the younger seme or the roles of seme and uke that can be exchanged. "Height rules", the implication that the taller person has greater strength, is also sometimes violated.

\section{Method}

This research will use an ethnographic approach, which is one of the qualitative research methods. Qualitative research that is data will be interpreted based on concepts and theories. According to Jane Stokes 
in her book entitled How to Do Media and Cultural Studies (2003), qualitative research is based on an interpretation of the world based on concepts that generally do not provide numerical figures, such as certain types of interviews. This study also uses in-depth interviews and participant observation with informants in cyberspace or commonly known as the "cyberetnography" method and Fujoshi's subject is taken indefinitely. Through in-depth interviews and participatory observations through cyberspace, it is expected to know what representations of Fujoshi's sexual fantasies about gays, especially in the yaoi genre. The researcher also tried to make fanfiction but not in the Yaoi genre and the researchers also participated in reading manga, fanfiction, and watching Yaoi videos. In this research, why only cover cyberspace? because "in Indonesia fans of love stories between men (Fujoshi) themselves, rarely show themselves in public. However, in fact the Fujoshi can easily be found among fans of Japanese culture. The internet is a very important media as a place to spread the popularity of boy's love, fans and writers of boy's love in Indonesia have succeeded in exporting boy's love stories, popularizing and enjoying it secretly by using internet media "(McHarry \& Pagliassotti, 2010). The data source comes from fanpage on Facebook, blogs and other virtual forums, and the author will draw conclusions based on observations from comments written by Fujoshi and yaoi forum users in the Chat Room sub-topic. In collecting data, researchers conduct participant observation or participatory observation to obtain natural and primary data. Researchers have been followers of Fujoshi and Yaoi fanpage on Facebook since 2012 and witnessed the development of fanpage and its users. The main focus of the scope of this research is Facebook.

\section{Informant Profile}

The informants in the study were drawn from a Facebook group named Fujoshi Indonesia. In 2015, informant A was twenty years old. Right now informant A is still in college. He was the first of three children to be together. The last education of his parents was high school. At first A liked Yaoi and eventually he became Fujoshi for five years ago, that was when he was fifteen years old. A has a Facebook account of his own as Fujoshi, so his family or friends don't know about it. Informant B. The first time the informant realized that he was Fujoshi when he was sitting in class X. Currently he was already sitting in class XI at a vocational high school. So it's been about one year to become Fujoshi. Informant B covered himself as Fujoshi from the family but eventually his brother and mother found out accidentally. Although hiding his identity as Fujoshi he admitted that he did not have a Facebook account or other social media as a Fujoshi. Informant B did not choose any of the Yaoi collections, whether they were videos, photos or films stored on his portable computer for fear of being discovered by his family at home and being scolded. Informant C, he has been Fujoshi since 2011 when he was 17 or 16 years old. At present his busy life is full-time work in a pharmaceutical factory. On weekends he enrolled in an extension program at one of the PTS. Informant C initially hid his identity from his family but now his mother already knows that he is Fujoshi. To his closest friends $\mathrm{C}$ is already open. He claimed to also have several LGBT friends, even he himself claimed to be bi-sexual. But informant $\mathrm{C}$ is currently trying to be as normal as possible, he began to leave the LGBT world slowly because he felt it had a negative influence on his social psychological life. Informant D. Informant D has liked Yaoi since three years ago when he was 15 years old. At present informant D is 18 years old. D just graduated from vocational school and intends to continue studying this year. Currently he has no routine activities and only spends time at home. Informant D does not have a special account as Fujoshi on any social media he has. He admitted if his friends knew that he was a Fujoshi, not even a few of his friends at school who were also Fujoshi. But in his family he made up for it. Informant E. Informant $E$ is still in semester two. Loved Yaoi from the start of 2012 when he was fifteen years old. Nowadays, E's daily life is studying and joining a number of organizations on campus. He was one of the informants who hid his identity as Fujoshi because of his family, and the environment in which he was still unable to accept with open arms gay people. But informant $\mathrm{E}$ did not hide from his friends, both in high school and now in college. Informant F, currently sitting in class XI, liked Yaoi for a long time, namely from class VII. In everyday life friends at school or friends who play outside of school only know that he does not have any social media accounts including Twitter or Facebook. Concerning collections related to yaoi, informant F said he had never bought, he once wanted to buy a yaoi snapback, but undoed it because he was afraid his parents would find out. So, the collection of Yaoi that has an F informant is only from downloading results on the internet. Informant G, currently in first grade in high school. He became Fujoshi since middle school. His family and friends at school did not know that he was a Fujoshi. Informant $\mathrm{G}$ claimed to have a special Facebook as Fujoshi to be free as Fujoshi without anyone opposing because he said that if his friends at school there were still many who opposed gay. He admitted that matters relating to LGBT had not yet been received in the community. He is also very fond of downloading yaoi videos. It is recognized that the Yaoi video collection has more than 500 videos and it has its own hard disk to store the Yaoi collection of images and videos that it has.

\section{Results and Discussion}

\section{Background Fujoshi likes Yaoi and his Representative Form}


The background of someone Fujoshi likes Yaoi is certainly different, but from Fujoshi who was interviewed by the researchers there were some similarities in the background of why they liked Yaoi and why they finally decided to become Fujoshi. From this the researcher decided to classify into some background reasons why Fujoshi liked Yaoi and explained what forms of representation the researcher found. Here are some background that this research often gets as a reason why Fujoshi can like the love story between men (gay) especially in the Yaoi genre. Some Fujoshi who researched this interview they claimed to be Fujoshi initially because they liked Japanese anime or manga and they were often referred to as Otaku. Otaku is a Japanese term that is used to refer to people who really pursue a hobby. Since the second half of the 1990s, the term Otaku began to be known outside Japan to refer to big fans of Japanese subcultures such as anime and manga, and some even call themselves Otaku. The following are the answers from the informants of this study who became Fujoshi because of the anime:

Informant A: I never thought that I would become Fujo, because I used to be really anti-gay, gay, etc. because I grew up in a religious family. At first I only intended to be friends with Naruto anime fans, but it turns out there are fujo. truzz he uploaded "a photo from sasukeXnaruto. because I was curious and interested, I tried asking" and he gave me an FFn link about SasuXNaru so from then I continued to be fujoshi.

Informant F: In the beginning, I was fad not Fujoshi. I just like Naruto and like reading fict straight. But, just when I'm bored I'm confused about what else to read. Well, while typing the word 'Sasu' found 'SasuNaru' initially confused. If translated, does that mean Sasuke x Naruto? Nah, I'm so confused. Aren't the two guys, right? Finally, right, when I open it, I feel really excited to see Yaoi (SasuNaru) turns out to be cuter and more exciting than straight. More than Naruto with girls, so does Sasuke. Initially, only mild Fujoshi. But leveling up like that after I was more immersed in yaoi things like this. Get to know a couple from another anime, continues to expand into the world of screenplay. The first fictional yaoi couple is KyuMin (Kyuhyun x Sungmin).

Informant G: "I became Fujoshi the first time after reading FF Sasunaru. Since then I love dying Sasunaru "

In Indonesia there are manga and anime fan communities. Usually, they get together and share with other fans via the internet or gather somewhere. Fans who are members of a community such as they make their own world towards something they admire, they interact with their neighbors, they show what they know and have to show that they are true fans in various ways, for example sacrificing to save their pocket money for buy collections related to yaoi. They also show themselves to form other people's impressions in a certain way so that they get influence, power, sympathy, and even they expect to be imitated by other fujoshi, or try to influence those who are not fujoshi to become fujoshi too. That is what this research found in Fujoshi who was the informant of this research who tried to be influential and could influence others to like the yaoi genre, usually starting from close friends who eventually also became Fujoshi. They also hope to be copied by others with wider coverage through cyberspace, so it's no wonder many of the anime and manga fans come to like the Yaoi genre because of these things. Some Fujoshi who researched this interviewed said they liked Yaoi because initially they were fans of anime and manga. There is one anime and manga that this research often found to be the reason Fujoshi finally liked Yaoi, the anime and manga "Naruto". Starting from fans who made a pairing between Sasuke and Naruto characters because some fans of the anime and manga especially women argued that even though Naruto and Sasuke competed and often fought in real stories, but there was a romantic side between Sasuke and Naruto so that "SasuNaru Couple" was created. Eventually, many people liked SasuNaru's pairing and nowadays, there are many fans of this anime and manga pairing. In fact, most fans of Naruto anime and manga, especially women, love the pairing of Naruto and Sasuke. Although those who like pairing do not always have to be Fujoshi, but you could say that many women who eventually became Fujoshi started from anime and manga fans like Naruto and Sasuke. When this research tried to googling on the internet a lot of articles about SasuNaru's closeness were concluded or composed by fans, then this research also found dialogues between SasuNaru which were considered romantic then made into articles by fans but usually the dialogs were from SasuNaru fanfiction quotes, not in the original anime or manga. So it is not uncommon for fans of SasuNaru couples to make fanfic love stories between SasuNaru which are actually far different from the original anime or manga and good fanfiction, fanart, etc. These are very easy to find on the internet. There are various genres of SasuNaru pairing made by fans ranging from the genre of brother romance, boy's love, to yaoi who include sexual scenes between Sasuke and Naruto. Here is a fanart example of a pairing between Sasuke and Naruto made by fans in various genres: 

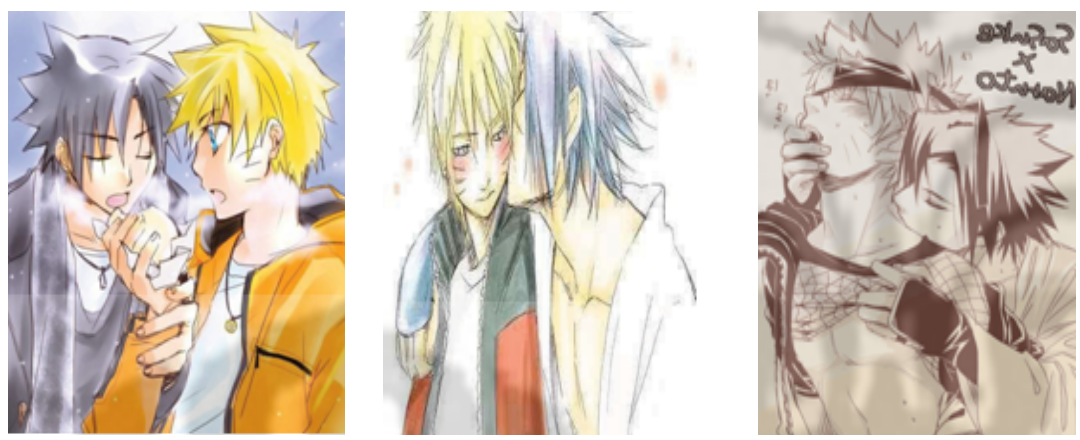

From the three pictures above, we can see all three genres, although there are similar love stories between men, but there are differences in the content of each picture. Usually from observations that this research makes if Brother romance only contains scenes of closeness between two men who are considered more for the reader, such as in the form of small concerns that are considered sweet by fans, then boy's love or Japanese term shonen-ai is a story romance between men which is only limited to holding hands or a short kiss and more romantic scenes, the last of the third picture can be seen if in the genre there are vulgar physical scenes, and that is one example of scenes that are easily found in the genre yaoi with even more description vulgar without censorship. In general fujoshi fans of SasuNaru pairings who were interviewed in this study liked all genres of "SasuNaru couple", although at first they didn't read the Yaoi genre directly. Usually the fujoshi who interviewed this research started from the brother romance genre and then progressed to boy's love and finally Yaoi. In fact, not infrequently like Yaoi in the form of BDSM. The research also found that there is a "SasuNaru Day" created by fans as SasuNaru's anniversary and is celebrated every year, which is every July $10^{\text {th }}$. Every date, fans will celebrate in various ways, one of which is by making fanart with good wishes. Here's an example of SasuNaru Day made by fans:

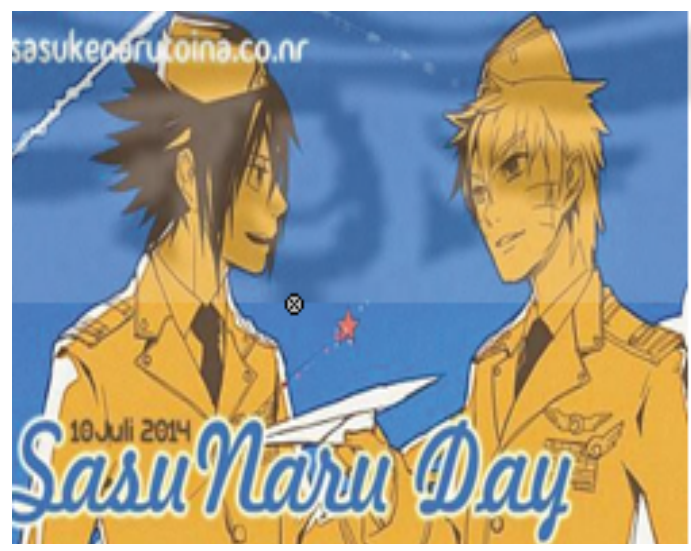

Besides that SasuNaru fans also do cosplay both in Japan, as well as in Indonesia and various other countries. Cosplay (Kosupure) is an English term made in Japan (wasei-eigo) derived from a combination of the words "costume" (costume) and "play" (play). Cosplay means the hobby of wearing clothes and accessories and makeup as worn by characters in anime, manga, fairy tales, video games, idol singers and musicians, and cartoon films. Cosplay performers are called cosplayers. Among fans, cosplayers are also abbreviated as cosers, and one of the talented cosplayers in Indonesia is Yukitora Keiji. In Japan, cosplay participants can be found at events held by fellow fans (dōjin circle), such as Comic Market, or attending concerts from music groups with a visual kei genre. Cosplay fans including cosplayers and non-cosplayers have spread all over the world, namely America, China, Europe, the Philippines, and Indonesia. SasuNaru fans also often do cosplay, not only wearing costumes like Sasuke and Naruto, fans of SasuNaru pairing also often be intimate to even vulgar posing with each other in order to explore the characters they play when they become cosplay from SasuNaru Couple. Those who do SasuNaru cosplay are really both men but there are also men and women and usually the Naruto are the women. Even fellow women play SasuNaru cosplay and have an intimate scene. Here is an example of cosplay from SasuNaru: 


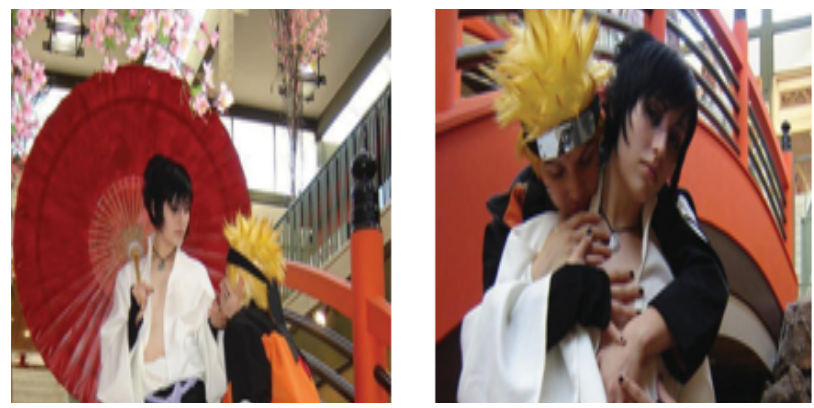

The picture above is a cosplay of Sasuke and Naruto played by a boy and a girl. Sasuke who wore an orange shirt was a man and who wore a white shirt playing himself as Naruto was a woman.
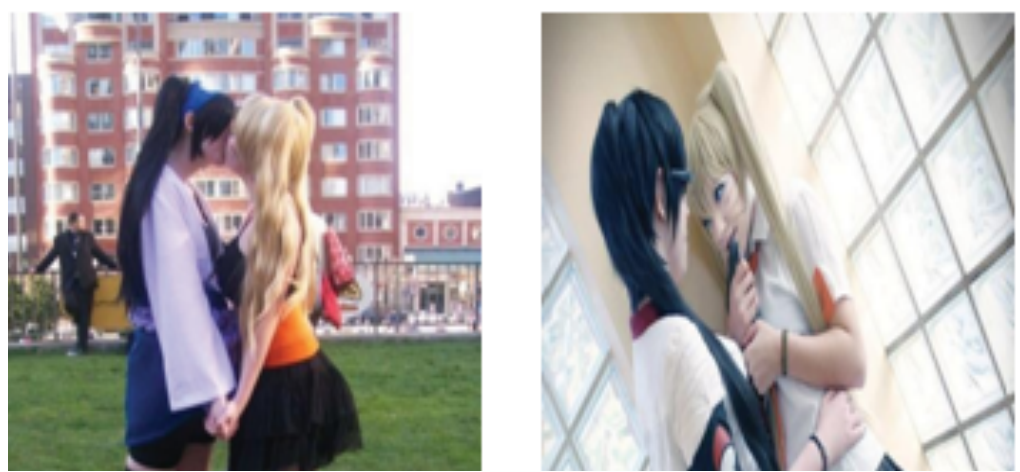

From the picture above the cosplay characters Sasuke and Narutonya are women, maybe a little different from the costume form of the characters Sasuke or Naruto in the anime or manga and also looks different from the previous four pictures. That is a cosplay character from Sasuke and Naruto wearing women's clothing. Adjusting to the gender they have but does not change the concept of cosplay that they play is SasuNaru Couple and that is considered legitimate when we participate in cosplay. In 1960 Berlyne put forward a theory about Curiosity or curiosity. According to Berlyne, uncertainty arises when we experience something new, surprising, unworthy, or complex. This will cause high stimulation in our central nervous system. Human response when facing an uncertainty is what is called curiosity or curiosity. Curiosity will direct humans to behaviors that try to reduce uncertainty (Gagne, 1985). Out of curiosity, this is one of the backgrounds of a woman becoming Fujoshi. As an example of the previous discussion about Naruto anime and manga. The Fujoshi were initially intrigued by the pairing of these two figures who were arguably quite excited and famous among Japanese anime and manga lovers, so that not a few became curious and began to find out about SasuNaru and eventually became addicted. After that began those who like the love story between men looking for other story titles that carry the love story between men. Which initially may only be in the form of the genre of brother romance or shonen-ai but gradually increased into the yaoi genre because it is considered the yaoi genre more challenging and more interesting. Informant $\mathbf{E}$ : "It used to be a bit disgusted at first. Because of reading Super Junior fanfiction yewook yaoi right. (pairing idols between Super Junior members Yesung and Reyowook). The story is good but it's a bit uncomfortable at first. But I'm curious to be able to read on and start to like Yaoi. There was a statement from one of my infotmen, informant D said that he doesn't like straight stories because he hates and dislikes the main female characters in the love story between men and women. He said if the main female character is often pretentious beauty and often spoiled the male main character so he feels fed up with straight genre stories. From there I asked the other informants what they thought was a straight story with the main character who was paired with a woman. Why do they prefer a male lead to be paired with a man than a woman. It turns out that some of their answers are the same. They feel they don't like the female lead.

Informant D: "I really hate girls who pretend to be cocky, pretentiously cute I just hate girls. especially if the girl in the anime is really cute. then the solution is cute guy + masculine guy be my beloved yaoi"

When I ask my informants about sexual fantasies, here are a few examples of quoted answers from them:

Informant B: About my fujoan fantasy, yes, it must be very often appear. When I saw two guys or more embracing each other, my mind had gone everywhere. The wildest fantasy, huh ... Uh, ahem hardcore, ahem so. Wild fantasy can be triggered by anime images, or real. Lately my mind began to shorten because several times I read the BDSM fanfic. 
Informant C: "I often bangt instead ... if there is a piggyback guy with his mind where have he been" ... there are guys both sitting beside me or sitting in public transportation even after reading the FF rated M likes to imagine the boys I meet you will BDSM hihihi ... (sorry for the boys).

\section{Conclusion}

Fujoshi's background likes the love story between men is certainly different. But from the research that this research has done there are several kinds of similarities, such as they became Fujoshi because they initially liked manga and anime, those who were curious about the yaoi genre, and those who felt bored with the love story between men and women, as well as various other reasons that made them finally addicted to the love story between men to have sexual fantasies between fellow men. Sexual fantasies possessed by Fujoshi certainly differ. But most Fujoshi will begin to fantasize when he sees two men close together either on the road or in public vehicles. Moreover, when they just read the yaoi story, their fantasies will get wilder or some of them also claim to imagine the man they met on the road when reading the Yaoi story.

\section{References}

Abraham, Y. (2008). Boys ee love thrives in conservative Indonesia. Dalam A. Levi, M. McHarry \& D. Pagliassotti (Ed.), Boys' love manga: essays on sexual ambiguity and cross-cultural fandom of the genre (pp. 44-55). North Carolina: McFarlan \& Company, Inc.

Boellstorff, T. (2005). The gay archipelago: seksualitas dan bangsa di Indonesia. New Jersey: Princeton University Press.

Cavanagh,Allison. 1999. Behavior in Public?:Ethics in Online Ethnography,Cybersociology 6,2.

Danim, Sudarwan. 2004. "Metode Penelitian untuk Ilmu-Ilmu Prilaku : pedoman penulisan majalah”, acuan dasar bagi mahasiswa Program Sarjana, Penelitian Pemula.Jakarta : Bumi Aksara.

Greenberg, A.n2009 "East Asian Studies : Homosexuality in Manga,"

http://www.annualglobalcollegeconference.com.

Haddock, G. \& Maio, G. R. (2004). Contemporary perspectives on the psychology of attitudes. New York: Psychology Press.

Hall, C. S, Lindsay, G \& Campbell, J. B, 1998."Theories of Personality”,(4th edition), John Wiley \& Sons, New York.

Miracle, Andrew W, dkk. 2002.“Human Sexuality, Meeting Your Basic Needs”, Pearson Education, New Jersey.

McHarry, Mark \& Pagliassotti, Dru. 2010. Boy’s loveManga. Essay on the Sexual Ambiguity and Cross Cultural Fandom of the Genre.McFarland \& Company :Jefferson.

Miracle, Andrew W, dkk. 2002. "Human Sexuality, Meeting Your Basic Needs”,

Pearson Education, New Jersey.

Nurizky, Fatia. 2012. Analisis Perubahan Perilaku Perempuan Penggemar Genre Boy's Love Melalu Forum Virtual di Dalam Cyberspace. Skripsi Published. Depok: Universitas Indonesia.

Pagliassotti, Dru. 2008. Reading Boy's love in the West. Journal Participations Volume 5, Issue 2 Special Edition, 1-10.

Paluck, E. L. (2009). Reducing intergroup prejudice and conflict using the media: a field experiment in Rwanda. Journal of personality and social psychology, vol. 96, no. 3, pp. 574-587.

Sanvoss, C. 2005. Fans: The mirror of consumption. Cambridge, MA: Polity

Stokes, Jane. 2007. "How To Do Media and Cultural Studies. Yogyakarta”: PT. Bentang

Pustaka.

Sueen, Noh. Tribun News. 2012. Survei : Orang Indonesia Lebih Suka Bergaul di Dunia Maya. http://www.tribunnews.com/iptek/2012/08/09/survei-orang indonesia- lebih-suka-bergaul-di-dunia-ma 